\title{
Risk Assessment of Extreme Events along a River Flow
}

\author{
Ivan K. Diadovski ${ }^{1}$, Maya P. Atanassova ${ }^{1}$, Vasil Simeonov ${ }^{2}$ \\ ${ }^{1}$ Central Laboratory of General Ecology, Bulgarian Academy of Sciences, Sofia, Bulgaria \\ ${ }^{2}$ Faculty of Chemistry, University of Sofia "St. Kl. Ohridski", Sofia, Bulgaria \\ E-mail:diadovski@hotmail.com,vsimeonov@chem.uni-sofia.bg \\ Received November 26, 2009; revised December 29, 2009; accepted February 10, 2010
}

\begin{abstract}
The present work considers the Struma River water flow on Bulgarian territory as a starting point for evaluation of maximum and minimum water flow using an original integral method. The risk assessment is determined by specific indices like the index $\mathrm{M}_{\max , \mathrm{i}}$ for the deviation of the maximum water flow from the calculated norm of the maximum flow $\mathrm{Q}_{\max , 0}$ and the index $\mathrm{M}_{\text {min, } \mathrm{i}}$ for the deviation of the minimum water flow from calculated norm of the minimum flow $\mathrm{Q}_{\min , 0}$. The new integral approach introducing specific indicators for risk assessment like the indices $\mathrm{M}_{\min , \mathrm{i}}$ and $\mathrm{M}_{\max , \mathrm{i}}$ has been checked at three sampling locations of the National monitoring net along the Struma River: Pernik (in the beginning), Krupnik (in the middle) and Marino pole (at the border in Greece) for the period 1948-2006. A significant trend towards decreasing of $\mathrm{M}_{\max , \mathrm{i}}$ index is outlined for the three points. On contrary, a significant trend towards increasing of $\mathrm{M}_{\min , \mathrm{i}}$ index is found at Krupnik and Marno pole sampling points.
\end{abstract}

Keywords: Integral Indices, Climate Impact, Water Quality, River Flow, Extreme Events

\section{Introduction}

The transboundary Struma River flows in the western part of Bulgaria and has a catchment area of $107.97 \mathrm{~km}^{2}$ and length of $290 \mathrm{~km}$. The catchment follows a mountain pattern and is characterized by a relatively low forestation level. The river water sources are in the high mountain part of the Vitosha and Rila Mountains. The Struma River flows through Bulgaria and Greece to the Aegean.

The Struma River catchment area is a part of a region that experiences the influence of European continental climate. The southernmost part of the river valley serves as a corridor for the Mediterranean climate impact. After Krupnik, the Struma River flow formation depends on the Mediterranean climate impact (Krupnik point - Marino pole point).

The EU Water Framework Directive (EU Directive) [1] prescribes good water quality as a goal for all water bodies within a given catchment. To achieve this status, each EU country should develop an optimal management strategy [2-4].

The water quantity of the Struma River is controlled at 6 hydrometric stations - Pernik, Razhdavitsa, Dupnitsa, Boboshevo, Krupnik, Marino pole, four of them being situated along the Strouma River (Figure 1).
The relief of the investigated area is diverse: the difference between the highest point $(2180 \mathrm{~m})$ and the lowest point at the Greek border $(270 \mathrm{~m})$ is significant. Preliminary studies have shown that the natural state of the river flow formation depends on the altitude [3].

The natural conditions of the Struma River flow formation are due to the climate impact, while the effect of the economic activity is insignificant. The Struma River is used for industrial water supply and for irrigation.

In the recent years many researchers focused their attention on climate changes due to anthropogenic activity [5-7].

Many authors believe that a period of warming will characterize the coming decades. Others are more reserved on the issue [8-10]. What can be pointed out is that the natural climate dependencies are disturbed by the anthropogenic impacts $[2,11]$.

Therefore, we believe that difficult for evaluation risk events due to climate changes at regional and global level could be assessed or even predicted if appropriate indicators are introduced. In previous papers the authors investigate the dynamics of the module coefficients $\mathrm{K}_{\mathrm{i}}$ as a background for integral assessment of the climatic impact on the river flow formation [12]. Usually, these module coefficients are applied for calculation of the coefficient of variation of the flow for a certain period. 


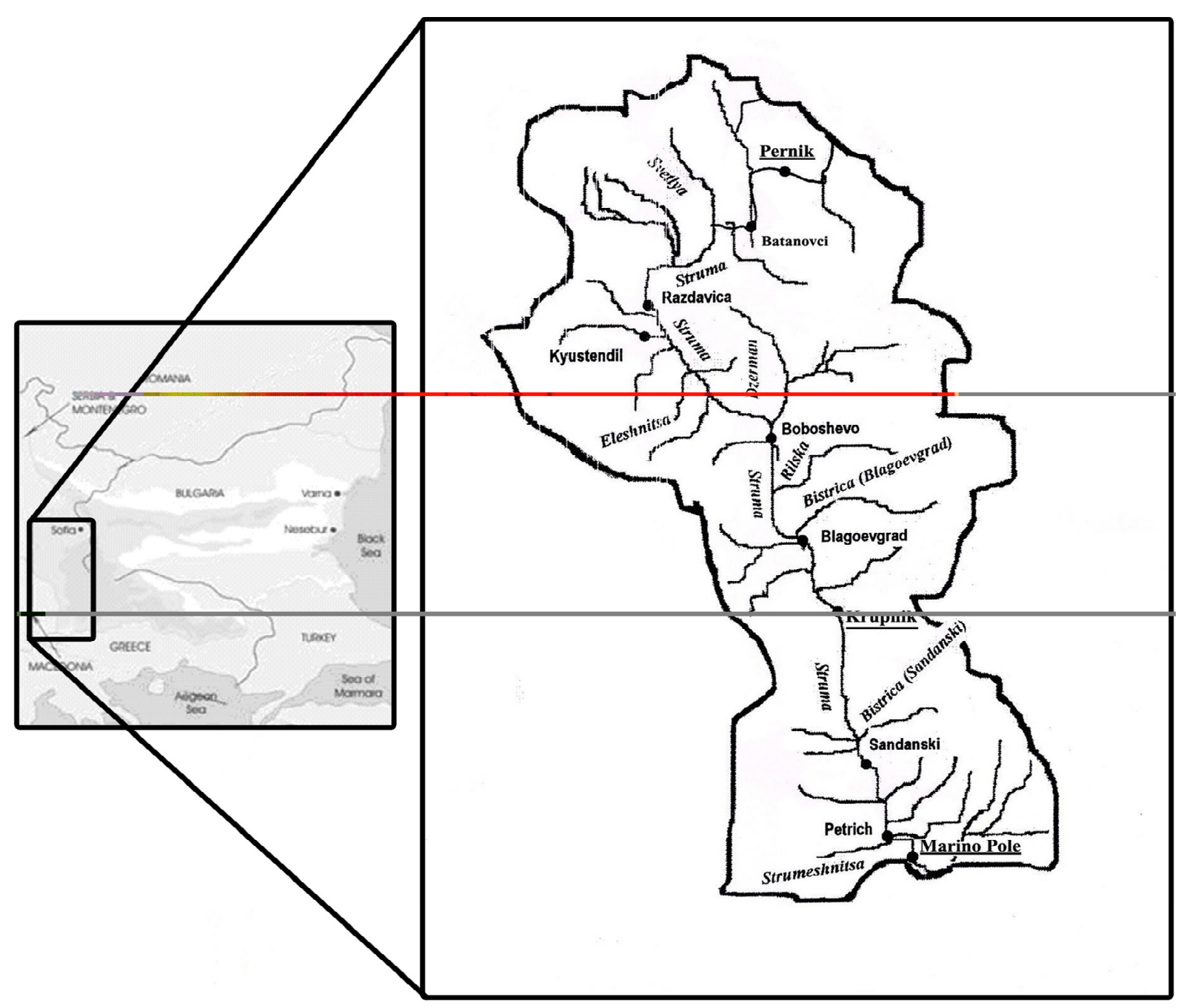

Figure 1. Catchment of the Struma River in Bulgaria.

new integral indices (coefficients) $M_{\max , i}$ and $M_{\text {min,i }}$ offered in the present study are an important development of the concept for the integral risk assessment. The authors are using the value of the norm for minimal and maximal water flow to formulate these new indicators for risk assessment of extreme events.

The topic of risk assessment of flood events is a priority for all EU countries. A special Framework Directive 2007/60/EO of the European Parliament and Council for management of the flood risk has been recently accepted. The present work considers a particular problem related to the management of the waters in a transboundary river basin. In principle, the results obtained could be used on a more large global scale.

The main objectives of this research are to study:

1) The tendency of the multi-annual dynamics of the absolute maximum values of the river flow with respect to the risk assessment of flood events during the period 1948-2006.

2) The tendencies of the multi-annual dynamics of the absolute minimum values of the river flow with respect of drought events.

\section{Materials and Methods}

The retrospective analysis of the river water flow dynamics is performed on the basis of information collected at the Pernik, Krupnik and Marino pole hydrometric stations. For this purpose the Origin 6.0 software (Origin 6.0 2002) [13] and software Programme Strouma [14] has been applied for data analysis.

Different functions were considered in the trend analysis for certain periods - linear, exponential, second and third degree polynomials. The type of the function describing the trend was determined on the basis of statistical criteria as correlation coefficients and Fishers tests [15-19]. The function representing the trend can be used for short-term (up to 1 year) prediction of the river flow dynamics, when it describes a significant trend. 
Statistical methods are used in hydrology for the assessment of climatic and anthropogenic impact on the river flow formation in a specific cross section of the river basin $[9,18,20]$. Usually, a statistical comparison of the natural and disturbed state of the river flow is performed in order to assess the climatic impact on the flow.

In the present work, an integral approach to evaluating the level of climate impact on the river flow formation is applied following earlier studies of Diadovski et al. [12, 21]. With respect to the risk assessment of flood or drought events specific integral indicators are introduced, which are based on the ratios between the highest water discharge for the year $\mathrm{Q}_{\max , \mathrm{i}}$ to the multi-annual-average value of the maximum water discharge $\mathrm{Q}_{\max , 0}$ and on the ratio between the minimum water discharge $\mathrm{Q}_{\min , \mathrm{i}}$ to the multi-annual-average value of the minimum water discharge $\mathrm{Q}_{\min , 0}$.

These relations represent indices, on the basis of which, the effect of the climatic and anthropogenic factors on flow formation has been determined. The norm for a certain parameter of the flow (average annual, maximal and minimal water flow) is the average value for a long-term period. The longer the period of observation, the less the error in calculation of the flow norm. The proposed approach is applied to the Struma River catchment on Bulgarian territory.

The proposed indices are:

$$
\begin{aligned}
& \mathrm{M}_{\text {max }, \mathrm{i}}=\mathrm{Q}_{\text {max }, \mathrm{i}} / \mathrm{Q}_{\max , 0} \\
& \mathrm{M}_{\text {min }, \mathrm{i}}=\mathrm{Q}_{\text {min }, i} / \mathrm{Q}_{\text {min }, 0}
\end{aligned}
$$

The fluctuations of the $\mathrm{M}_{\max , \mathrm{i}}$ and $\mathrm{M}_{\min , \mathrm{i}}$ indices for a certain period give the possibility of making integral assessment of the climatic and anthropogenic impact on the river flow formation on a river basin scale and risk assessment along the Struma river flow using extreme events of the past and integral indices.

For maximal water flow values higher than the norm $\left(\mathrm{M}_{\max , \mathrm{i}}>1\right)$ one could account for extreme events (floods) which happened in the past. The higher the integral indices $\mathrm{M}_{\text {max, } \mathrm{i}}$ than 1 , the higher the flood risk. It means that the higher the level of deviation of the maximal water flow values from the norm $\left(\mathrm{Q}_{\max , 0}\right)$, the higher gets the risk of flooding $\left(\mathrm{M}_{\max , \mathrm{i}}>2\right)$.

For minimal water flow values lower than the norm $\left(\mathrm{M}_{\min , \mathrm{i}}<1\right)$ for a certain period one could account for extreme events (draughts) which happened in the past. The lower the integral indices $\mathrm{M}_{\min , \mathrm{i}}$ than 1, the higher the draught risk. It means that higher the level of deviation of the minimal water flow values from the norm, the higher gets the risk of draught $\left(\mathrm{M}_{\min , \mathrm{i}}<0.5\right)$.

This hypothesis was checked using data from the sampling station Pernik, Krupnik and Marino pole.

Based on the results, one can specify different levels of correlation between time and index values. Due to the basic statistics of the input data, the Spearman correlation coefficient was used throughout the study. Although no exact numbers are given, according to different environmetric studies $[3,21,22]$ the correlation could be interpreted in the following empirical manner:

For $0.2<\mathrm{r}<0.3$ - slight tendency;

For $0.3<\mathrm{r}<0.5$ - moderate tendency;

For $0.5<\mathrm{r}$ - significant tendency.

These values have significance and interpretation only if the number of observations is above 30 . In this study it is accepted that the length of the period of observation for calculation of the integral indices is equal to the period used for calculation of the river flow norm. In calculating the coefficient of variation of the hydrological parameters $C_{v}$ a period of observation $\mathrm{n}>30$ years as a necessary condition for calculation according to the empirical formula:

$$
C_{v}=\sqrt{(K i-1)^{2} \frac{1}{n}}
$$

For small changes in the values of the different hydrological parameters and of the integral indices a shorter period of observation is needed, and vice versa. In order to check the significance of the correlation coefficient, the calculated value is compared with the theoretical one, which represents in fact the $r$ significance test $[16,17,22]$.

\section{Results and Discussion}

According to Amoros [5] and Sing [18], the fluctuations of climate and physical geographic characteristics provoke trends, including leap-like (catastrophic) events.

In our study the trends of the basic characteristics of the river flow on the basis of integral parameter $\left(\mathrm{M}_{\max , \mathrm{i}}\right.$, $\mathrm{M}_{\text {min, } \mathrm{i}}$ indices) at the Pernik, Krupnik and Marino pole stations are determined.

The theoretical correlation coefficient of the trend functions at degrees of freedom No $=59$ and a probability of error $\alpha=5 \%$ has a value $r=0.25$. The calculated values of the correlation coefficients for the investigated period are in the interval between 0.20 and 0.59 . This fact shows that the model for the trend characterizes adequately moderately expressed tendency and significant tendency. The confidence intervals of the annual averages indices $\mathrm{K}_{\mathrm{i}}, \mathrm{M}_{\max , \mathrm{i}}, \mathrm{M}_{\min , \mathrm{i}}$ are between 0.01 and 0.05 .

The assessment of the flow change in the hydrometric stations of Pernik, Krupnik and Marino pole for period of 59 years (1948-2006) is made on the basis of integral parameter dynamics (Table 1).

The variation coefficient $\mathrm{CV}$ of the annual average water flow has values of $0.38,0.41$ and 0.33 for the sites Pernik, Krupnik and Marno pole, respectively.

The trend in the dynamics of the $\mathrm{M}_{\max , \mathrm{i}}$ index is described best by a linear function with a correlation coefficient $\mathrm{R}=-0.52$ for Pernik (Figure 2), $\mathrm{R}=-0.58$ for 
Table 1. Dynamics of the river flow water characteristics.

\begin{tabular}{cccc}
\hline Sampling site & $\begin{array}{c}\mathrm{Q}_{0} \text { (multi-annual average river } \\
\text { flow) }\end{array}$ & $\begin{array}{c}\mathrm{Q}_{\max , 0} \text { (multi-annual average maximum } \\
\text { river flow) }\end{array}$ & $\begin{array}{c}\mathrm{Q}_{\text {min }, 0} \text { (multi-annual average mini- } \\
\text { mum river flow) }\end{array}$ \\
\hline Pernik & $2.11 \mathrm{~m}^{3} / \mathrm{s}$ & $31.42 \mathrm{~m}^{3} / \mathrm{s}$ & $0.72 \mathrm{~m}^{3} / \mathrm{s}$ \\
Krupnik & $45.90 \mathrm{~m}^{3} / \mathrm{s}$ & $310.63 \mathrm{~m}^{3} / \mathrm{s}$ & $6.89 \mathrm{~m}^{3} / \mathrm{s}$ \\
Marino pole & $72.42 \mathrm{~m}^{3} / \mathrm{s}$ & $443.85 \mathrm{~m}^{3} / \mathrm{s}$ & $10.52 \mathrm{~m}^{3} / \mathrm{s}$ \\
\hline
\end{tabular}

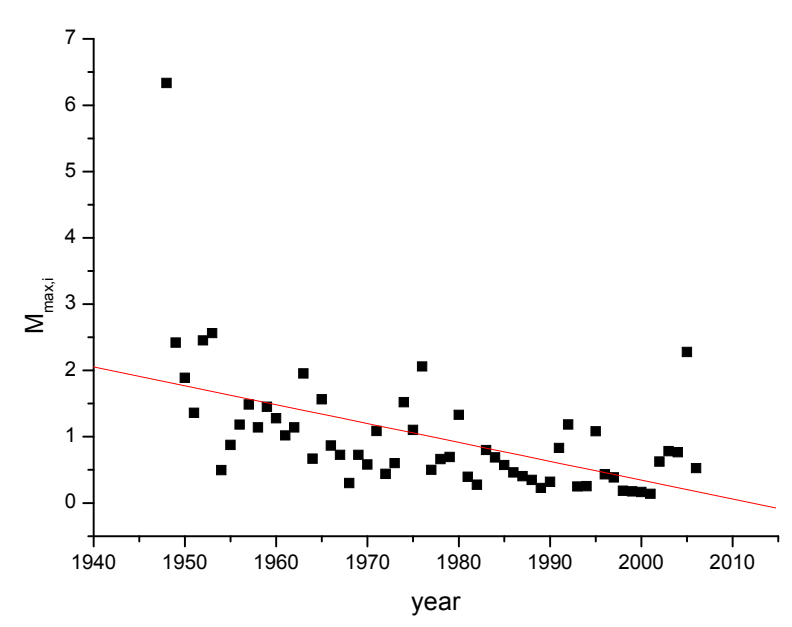

Figure 2. Dynamics of the $M_{\text {max, }}$ index for the Struma River at the Pernik point.

Krupnik (Figure 3) and $\mathrm{R}=-0.55$ for Marino pole (Figure 4). Two periods are defined for the three sampling points with respect to $\mathrm{Q}_{\max , 0}$ index, namely a period with maximum water flow higher than the average multiannual value and $\mathrm{M}_{\text {max,i }}>1$ with flood effect danger (1948-1975) and another period characterized by maximum water flow lower than the average multi-annual value $\left(\mathrm{M}_{\max , \mathrm{i}}<1\right.$ for $\left.1976-2006\right)$.

A significant trend towards decreasing of the $\mathrm{M}_{\text {max, } \mathrm{i}}$ index is outlined, which corresponds to the trend towards diminution of the maximum water flow $Q_{\max , i}$ for three points.

The values of $\mathrm{M}_{\mathrm{max}, \mathrm{i}}$ in the Pernik point vary within the range 0.3-6.2, which indicates that both higher and lower maximum water flow than the norm (average multiannual value of the maximum water flow) is observed.

Years with hazardous flooding are outlined $\left(\mathrm{M}_{\text {max,i }}>\right.$ 2), for example1950-1953, 1962, 1965, 1975, 2005. It has to be noted that the years with values of the maximum water flow $\mathrm{Q}_{\text {max,i }}$, which are lower or insignificantly higher than the norm of the maximum water flow for the considered period, are predominant.

The values of $\mathrm{M}_{\text {max,i }}$ in Krupnik vary within the range $0.25-2.3$, which indicates that in certain years the maximum water flow $Q_{\max , i}$ significantly exceeds the norm of the maximum water flow $\mathrm{Q}_{\max , 0}$, forming in this way hazardous floods. Years with hazardous flooding are outlined as 1955-1958, 1975.

The values of $M_{\max , \mathrm{i}}$ in the Marino pole point vary within the range $0.25-2.4$, which indicates that in certain years the maximum water flow $\mathrm{Q}_{\max , \mathrm{i}}$ significantly exceeds the norm of the maximum water flow $\mathrm{Q}_{\max , 0}$, forming in this way hazardous floods. Years with hazardous flooding are outlined as 1954-1956, 1975.

The trend in the dynamics of the $\mathrm{M}_{\min , \mathrm{i}}$ index for Pernik (Figure 5) is described by a $3^{\text {rd }}$ order polynomial

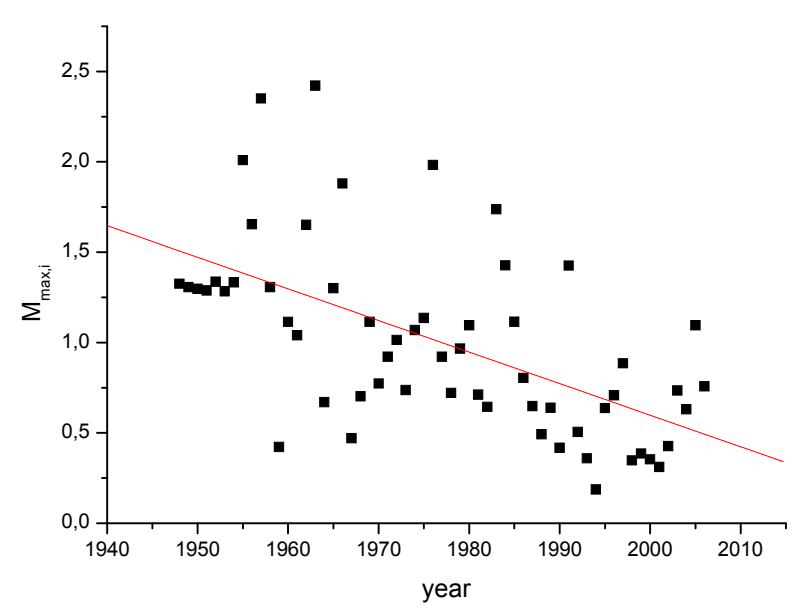

Figure 3. Dynamics of the $M_{\text {max, }}$ index for the Struma River at the Krupnik point.

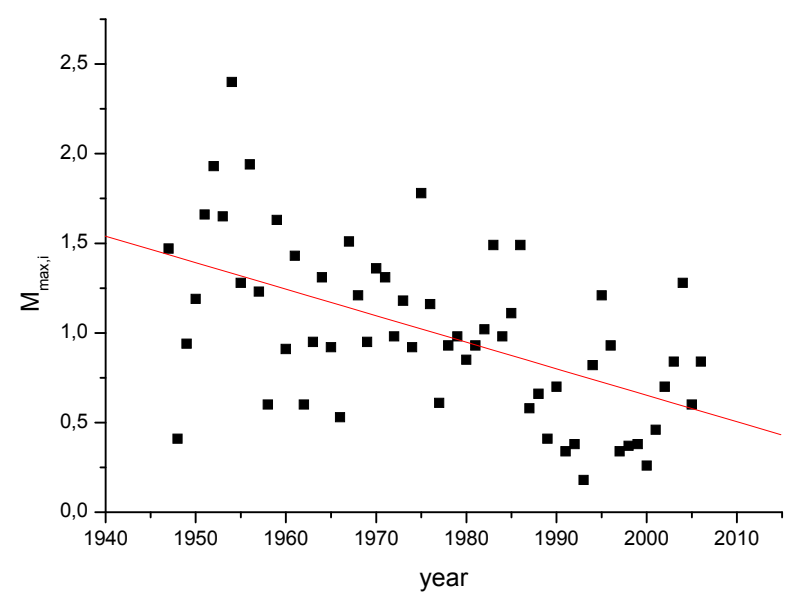

Figure 4. Dynamics of the $M_{\text {max, }}$ index for the Struma River at the Marino pole point. 


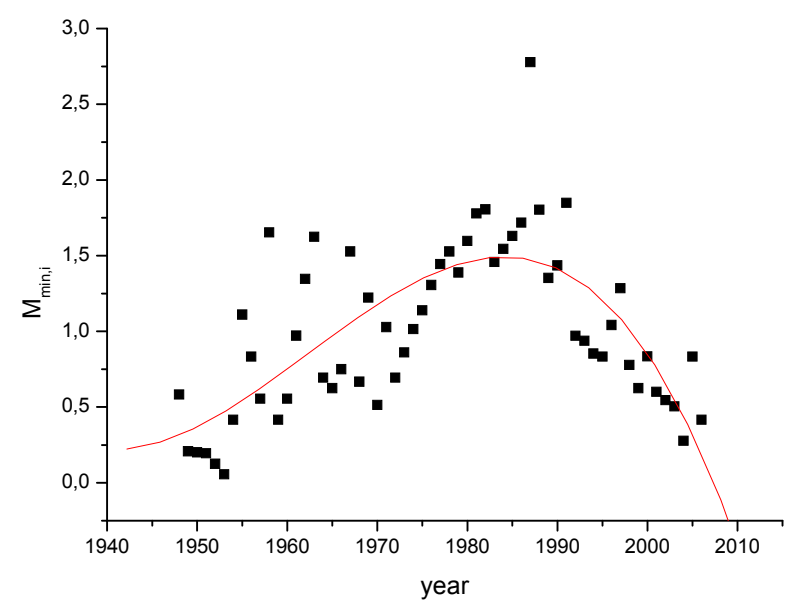

Figure 5. Dynamics of the $M_{\text {min, } i}$ index for the Struma River at the Pernik point.

with a value of the correlation coefficient $\mathrm{R}=0.54$ and by a linear function with $\mathrm{R}=0.21$ for Krupnik (Figure 6) and $\mathrm{R}=0.36$ for Marino pole (Figure 7 ).

The value of the correlation coefficient $r=0.21$ at Krupnik site indicates that the linear function describes a slight tendency in the dynamics of $\mathrm{M}_{\min , \mathrm{i}}$. The correlation coefficient is close to the theoretical significant value of 0.25 . A slight tendency could be therefore accepted.

A significant trend towards increasing values of the $\mathrm{M}_{\text {min,i }}$ index is outlined, which corresponds to the trend towards increasing of the minimum water flow $\mathrm{Q}_{\text {min, } \mathrm{i}}$ for the Krupnik and Marno pole points. The trend shows variable tendency to increasing during the interval 19481988 and to decreasing during the period 1989-2006 for the Pernik point.

The conclusion can be made that a trend is established towards increasing the values of the ratio between the minimum water flow $\mathrm{Q}_{\min , \mathrm{i}}$ and the average multi-annual value of the minimum water flow $\mathrm{Q}_{\min , 0}$ for the considered period.

The values of $\mathrm{M}_{\min , \mathrm{i}}$ in Pernik vary within the interval $0.2-2.5$, which indicates that years with minimum water flow, significantly lower than the norm of the minimum water flow $\left(\mathrm{Q}_{\min , 0}\right)$, are observed, thus forming hazardous drought periods $\left(\mathrm{M}_{\min , \mathrm{i}}<0.5\right)$. These years are 1950-1953, 1960, 1970, 2000- 2005.

The values of $\mathrm{M}_{\min , \mathrm{i}}$ in Krupnik vary within the range $0.2-3$, which indicates that years with minimum water flow, significantly lower than the norm of the minimum water flow $\left(\mathrm{Q}_{\min , 0}\right)$, are outlined, thus forming hazardous drought periods. Such years are 1948, 1951-1953, 1959 1961, 1969, 1972, 1988, 1989, 1993, 1994, 1999 and 2001. During the considered period the years with minimum water flow higher than the norm of the minimum water flow $\left(\mathrm{Q}_{\min , 0}\right)$ are predominant.

The values of $M_{\min , \mathrm{i}}$ in Marino pole vary within the interval $0.2-2.3$, which indicates that years with mini- mum water flow, significantly lower than the norm of the minimum water flow $\left(\mathrm{Q}_{\min , 0}\right)$, are observed, thus forming hazardous drought periods. These years are 1948-1953, 1963, 1978, 1985-1990, 1992, 1993, 2000 and 2001.

The years with extreme events like floods and draughts already happened in the samplings sites-Pernik, Krupnik and Marino pole presented in Table 2.

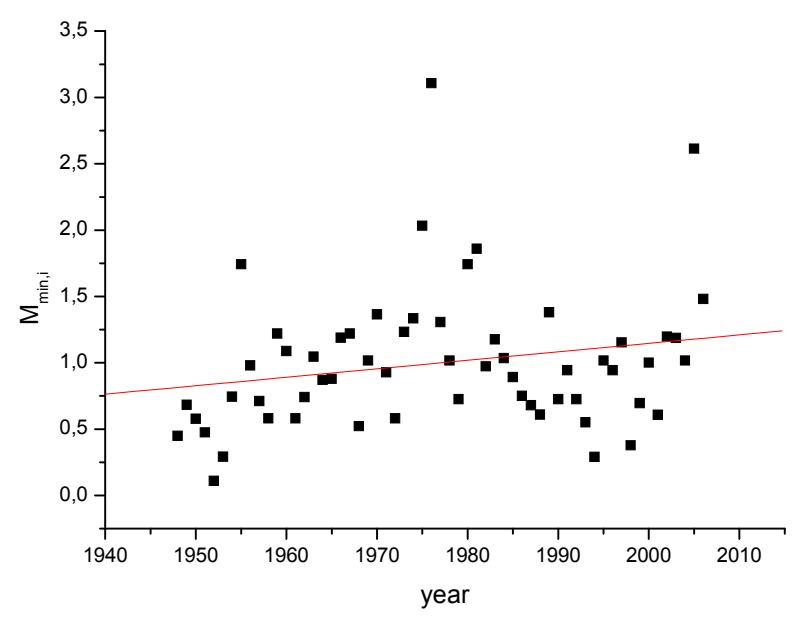

Figure 6. Dynamics of the $M_{\text {min,i }}$ index for the Struma River at the Krupnik point.

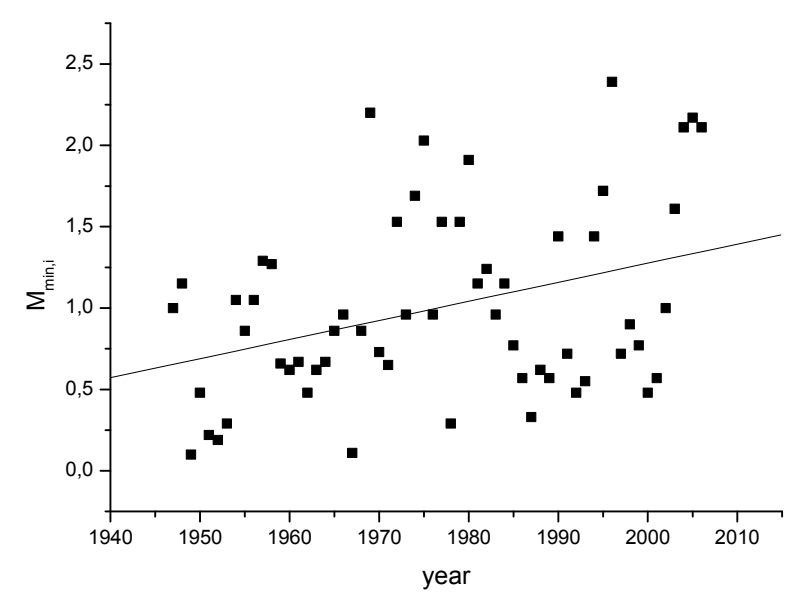

Figure 7. Dynamics of the $\mathbf{M}_{\text {min, } \mathrm{i}}$ index for the Struma River at the Marino pole point.

Table 2. Years of extreme events for sampling site.

\begin{tabular}{ccc}
\hline $\begin{array}{c}\text { Sampling } \\
\text { sites }\end{array}$ & Years of flood events & $\begin{array}{c}\text { Years of draught } \\
\text { events }\end{array}$ \\
\hline Pernik & $1950-1953,1962$, & $1950-1953,1960$, \\
& $1965,1975,2005$ & $1970,2000-2005$ \\
\hline \multirow{2}{*}{ Krupnik } & $1955-1958,1975$ & $1948,1951-1953,1959$ \\
& & $1961,1969,1972$, \\
& & $1988,1989,1993$, \\
& & $1994,1999,2001$ \\
\hline \multirow{2}{*}{ Marino pole } & $1954-1956,1975$ & $1978-1953,1963,1985-1990$, \\
& & $1992,1993,2000$, \\
& & 2001 \\
\hline
\end{tabular}


Two periods are outlined at the river points for the changes in the minimum water flow.

The 1948-1974 period is characterized by minimum water flow, which is lower than the average multi-annual value $\mathrm{Q}_{\min , 0}\left(\mathrm{M}_{\min , \mathrm{i}}<0.5\right.$ - low water and drought effect; $\mathrm{M}_{\text {min,i }}<1$-low water, possible negative effect). For the three points a three-year cycle is outlined (1961-1964), when the minimum water flow is higher than the average multi-annual value $\mathrm{Q}_{\min , 0}$.

The 1975-2006 period is characterized by minimum water flow, which is higher than the average multi-annual value $\mathrm{Q}_{\min , 0}\left(\mathrm{M}_{\min , \mathrm{i}}>1\right)$. For the three points a four-year cycle is outlined (1998-2001), when the minimum water flow is lower than the average multi-annual value $Q_{\min , 0}$.

Studying the dynamics of the indices $\mathrm{M}_{\max , \mathrm{i}}$ and $\mathrm{M}_{\min , \mathrm{i}}$ it could be found that for one same sampling site and one and the same time period extreme events of two types are observed-floods and draughts. This event could be explained by the climatic changes and the physicalgeographical conditions along the Strouma River catchment.

The anthropogenic effects in Struma River catchment like decrease of the forest area, building of hydrotechnical units etc. are negligible. The dynamics of the absolute maximal and minimal water flows is formed under the influence of climatic factors (Mediterranean climatic impact) and of the geographical and hydrological characteristics of the catchment (area, population, average height above the sea level, slope) and the dynamics of the indices $\mathrm{M}_{\max , \mathrm{i}}$ and $\mathrm{M}_{\text {min,i }}$ determine the extreme events in the period of consideration. It could help in assessment of future extreme events. The tendencies towards decrease of the absolute maximal water flow and increase of the absolute minimal water flow (Krupnik and Marino pole) could be taken as reason not to expect extreme events in near future. For site Pernik it could be expected seasons of draughts due to the decreasing tendency of $\mathrm{M}_{\min , \mathrm{i}}$ in the last 20 years.

Using the dynamics of the integral indices $M_{\text {max,i }}$ and $\mathrm{M}_{\text {min,i }}$ and information on extreme events from the past a preliminary risk assessment of future extreme events such as floods and droughts could be made.

Flood effects during high water are observed during the years with $M_{\max , i}>2$, while for the years with $M_{\max , i}$ $>1$ high water with possible negative effect may be observed.

Low water with possible negative effect is observed during the years with $\mathrm{M}_{\text {min,i }}<1$, while for the years with $\mathrm{M}_{\text {min,i }}<0.5$ low water with drought effect may be observed.

The following conclusions may be drawn on the basis of the performed assessment of the integral indices dynamics.

A stable trend is observed towards decreasing of the maximum water flow $\left(\mathrm{M}_{\max , \mathrm{i}}\right)$ during the considered period for three points (Pernik, Krupnik and Marino pole).
A stable trend is observed towards increasing the minimum water flow during the considered period for the Krupnik and Marino pole points. A trend showing variable tendency towards increasing and decreasing of the minimum water flow during the considered period is established for the Pernik point.

The presented results confirm the importance of using the integral assessment of the climatic and anthropogenic impact within a catchment as a reliable tool for water management.

\section{Conclusions}

From the experimental results obtained, the following conclusion can be drown:

The character of the changes in the maximum water flow at the three river points with respect to the average multi-annual value of the maximum water flow $\mathrm{Q}_{\max , 0}$ is the same. The character of the changes in the minimal water flow at the same sampling points with respect to the average multi-annual value of the minimum water flow $\mathrm{Q}_{\min , 0}$ is one and the same, too.

The proposed integral indices provide the possibility of evaluating the climate impact on the Struma River flow formation, but they may also be applied for other rivers on regional, national and transboundary level. Using integral indicators, high water years, dry years, maximum water flow and flood effect, minimum water flow and drought effect, are identified, which is a preliminary estimation of the risk assessment of flood events and drought events.

With the proposed integral parameters it is possible to investigate the influence of climate on the formation of the average annual maximum/minimum water flow and to establish and predict possible short-term negative effects.

\section{Acknowledgements}

The authors would like to express their sincere gratitude for the financial support (project DO-02-352) by the National Science Found.

\section{References}

[1] European Union Commission, "Water Framwork Directive," Brussels, 2000.

[2] I. Diadovski, S. Bratanova-Doncheva, Y. Raykovska, N. de Pauw and D. Rousseau, "Integral Assessment of Economic Activity Impact on River Flow Formation," Journal of Balkan Ecology, Vol. 7, No 2, 2004, pp. 211-216.

[3] I. Diadovski, M. Petrov, T. Ilkova and I. Ivanov, "A Model for the Mesta River Pollution Assessment Based on the 
Integral Indices," Chemical and Biochemical Engineering Quarterly, Zagreb, Vol. 19, No. 3, 2005, pp. 291-296.

[4] M. Meybeck and G. de E. Fustec, "La Seine et son bassin”, Elsevier, Paris, 1998.

[5] C. Amoros and G. Tetts, "Hydrosysteme Fluvieux," Musson, Paris, 1993.

[6] B. Bilger, "Global Warming: Earth at Risk", Chelsea House Publishers, New York, 1992.

[7] R. H. McGuen, "Hydrologic Analysis and Design," Prentice Hall, New York, 1989.

[8] M. G. Anderson and T. P. Burst, "Hydrological Forecasting", John Willey and Sons, Chichester, 1985.

[9] Y. Tardy, "Le cicle de l'eau, Climates, Paleoclimats et Geochemie Global, " Masson, Paris, 1986.

[10] A. Ward and W. Elliot, "Environmental Hydrology", Levis Publishers, New York, 1998.

[11] U. Braukmann and I. Pinter, "Concept for Integrated Ecological Evaluation of Running Water," Acta Hydrochimia and Hudrobiologia, Vol. 25, No. 30, 1997, pp. 113-127.

[12] I. Diadovski, M. Atanassova and I. S. Ivanov, "Integral Assessment of Climate Impact on Transbounadry Mesta River Flow Formation in Bulgaria," Environmental Monitoring and Assessment, Vol. 127, No. 1-3, April 2007, pp. 383-388. http://dx.doi.org/10.1007/s10661-0069287-5

[13] Microcal Software Inc., "Origin 6.0 Getting Started Manual," 7th Edition, Northampton, 2002.

[14] I. Diadovski, M. Atanassova and V. Simeonov, "Guide

\section{Notation}

$\mathrm{M}_{\text {max,i }}$-ration between the maximum water flow $\mathrm{Q}_{\max , \mathrm{i}}$ and the calculated norm of the maximum flow $\mathrm{Q}_{\max , 0}$ $\mathrm{M}_{\text {min,i }}$-ratio between the minimum water flow $\mathrm{Q}_{\min , \mathrm{i}}$ and the calculated norm of the minimum flow $\mathrm{Q}_{\min , 0}$.

$\mathrm{Q}_{0}$ - multi-annual average river flow

$\mathrm{Q}_{\max , 0}$ - multi-annual average maximum river flow

$\mathrm{Q}_{\min , 0}-$ multi-annual average minimum river flow for Application to the Programme for Statistical Analysis from Monitoring Data, Modeling and Water Quality Assessment on the Strouma River," PublishScieSet-Eco, Sofia, 2008.

[15] L. Sachs, "Angewandte Statistik: Anwendung Statistischer Methoden," Springer Verlag, Berlin, 1971.

[16] V. Simeonov, "Principles of Data Treatment of Analytical Results," Sofia University Press, Sofia, 1997.

[17] P. Simeonova, V. Simeonov and G. Andreev, "Water Quality Study of the Struma River Basin, Bulgaria," Central European Journal of Chemistry, Vol. 1, No. 2, 2003, pp. 121-136.

[18] V. Sing, "Environmental Hydrology," Kluwer Academic Publishers, Dordrecht, 1995.

[19] R. Stegmann, et al., "Anwendung einer Zeitreihenanalyse in der Wassergütewirtschaft, " Wasser und Boden, Vol. 3, 1978, pp. 50-54.

[20] R. W. Heschy and R. Fairbridge, "Encyclopedia of Hydrology and Water Researches," Kluwer Academic Publishers, Dordrecht, 1998.

[21] I. Diadovski, M. Petrov, L. Brankova and E. Bournaski, "Integral Pollution Assessment of the Mesta River in Bulgaria," Journal of Environmental Protection and Ecology, Vol. 5, No. 3, 2004, pp. 487-494.

[22] A. Astel, S. Tsakovski, P. Barbieri and V. Simeonov, "Comparision of Self-Organizing Maps Classification Approach with Cluster and Principal Components Analysis for Large Environmental Date Sets," Water Research, Vol. 41, No. 19, 2007, pp. 4566-4578.

$\mathrm{Q}_{\min , \mathrm{i}}$ - absolute minimum water discharge for year i

$\mathrm{Q}_{\max , i}-$ absolute maximum water discharge for year $\mathrm{i}$ $\mathrm{CV}$-coefficient of variation of the hydrological parameters

$\mathrm{K}_{\mathrm{i}}$-ratio between annual average river flow $\mathrm{Q}_{\mathrm{i}}$ for year $\mathrm{i}$ at a control site along the river and multi-annual average river flow $\mathrm{Q}_{0}$ for period of $\mathrm{n}$ years.

$\mathrm{n}$-period of observation

$\mathrm{R}$-coefficient of correlation 